\title{
A MORALIZAÇÂO DAS VERGONHAS NATURAIS NA LITERATURA PORTUGUESA DO SÉCULO XVI
}

\author{
José Augusto Mourão \\ Universidade Nova de Lisboa - Portugal
}

Andam sempre nus e, por bragas, trazem cascas de árvores, com que cobrem as vergonhas.

Pedro de Sintra

O homem e a mulher estavam nus, e não se envergonhavam.

(Gen. 2, 25)

Dire "je", comme le fait Adam, équivaut a ceci: voilà mon corps, je ne peux jamais le voir comme l'autre le voit.

Per A. Brand

\section{RESUMEN}

Cotejam-se aqui os discursos teológico-literário sobre a natureza da sexualidade, partindo da carta a el-rei D. Manuel de Pêro Vaz de Caminha e do Diálogo da viciosa vergonha de João de Barros, do teatro de José de Anchieta e outros, que moralizam as paixões, ou em nome da cultura que representam, ou em seu próprio nome, enquanto implicados na cena passional. A moralização das vergonhas naturais é vista como um processo da reinvenção do corpo e como o controlo do contágio passional.

\section{SUMMARY}

Theological-Literary Discourses on the nature da sexuality are compared and contrasted taking as a starting point the letter to king Manuel de Pêro Vaz de Caminha, João de Barros Diálogo da viciosa vergonha, the theatre of José de Anchieta and others who moralize the passions either in the name of the culture which they represent, or in their own name, as being in some way involved in the passions scene. The moralisation of natural feelings of shame is seen as a way of reinventing the body and of controlling passionate contagion. 


\section{JOSÉ AUGUSTO MOURÃO}

O encontro com o Outro é, antes de mais, um confronto do olhar. Etnocêntrico. Os outros são as nossas verdadeiras viagens, como M. de Certeau dizia. A relação é a lei, na vida dos grupos ou na experiência dos encontros. Da variação das ópticas se pode inferir da maior ou menor capacidade de integração da diferença. É assim que a visão de Gândavo não coincide com a de Francisco Soares, nem a visão de Zurara com a de Caminha. "Saber" o outro, a sociedade, o divino, não será um projecto fundamentalmente contraditório, fora dos limites do mesmo, isto é, da razão? Como conversar com o outro, quando se é precedido pelo carro triunfal da Verdade, não acreditando que haja, entre nós, uma ética a praticar? Mesmo a Verdade não admite outra força que a da luz: requer a liberdade. Os missionários reduziam o índio com armas diferentes das do colono, com a liberdade em vez da escravidão, pois qualquer conduta dirigida a ele era de indeclinável preceito que fosse baseada sobre $o$ princípio de estabelecida liberdade e de mansidão infantil, substituindo-se o que era possivel substituir, tudo com uma finura de quem vai tratar com meninos desconfiados, escreve Jorge de Lima ${ }^{1}$, mas isso era ainda redução. Substituir as monódias guerreiras, a pancada ritmada, o golpe, a percussão pelo canto gregoriano, "tão humilde e tão dogmático" (Jorge de Lima) ou pelo violino era ainda uma outra forma de trazer o outro ao mesmo, como Manuel da Nóbrega sabia. O Diálogo sobre a conversão do gentio, de Manuel da Nóbrega (Baia 1556-1557) dá-nos uma versão bem menos idílica que Vaz de Caminha sobre as relações dos Portugueses com os Indios. E começa aqui questão da ética da comunicação: se o outro me aparece na figura dos bambini colla barba, a expressão é de Muratori, como poderei eu vê-lo numa posição de altura, como diria Levinas? Não consistiu a relação com o Outro (o índio, o africano) em reduzi-lo ao império da língua, da religião, da natureza, da alimentação, do Mesmo?

A "conquista" não foi vista em parte nenhuma sem dissenso. Em 1549, a pedido de Las Casas, as universidades de Alcalá e de Salamanca proibem a impressão de um livro publicado em Roma pelo doutor Juan Gines de Sepúlveda, com o título de $D e$ mocrates II em que o cónego justifica o emprego da forca contra os bárbaros que são os Indios, arrimado à tese de Aristóteles sobre os escravos por natureza. Carlos V chega a ordenar o fim das expedições de conquista na América e provoca uma reunião no verão de $1550 \mathrm{em}$ Valladolid em que se sentam 14 teólogos para ouvir os dois defensores de Las Casas e de Sepúlveda. Confrontam-se as observações dos exploradores e dos missionários com as categorias de Aristótele acerca do "selvagem", do "bárbaro" do "estado de natureza". Las Casas levará a melhor sobre Sepúlveda: a evangelização implica uma mudança de vida, mas respeitando o modo de vida; não destruindo a natureza e a cultura dos Indios, mas inserindo um fermento de conver-

I De Lima, JoRge (1934) Anchieta, Rio de Janeiro, Civilização Brasileira, p. 103. 


\section{A MORALIZAÇÃO DAS VERGONHAS NATURAIS NA LITERATURA PORTUGUESA DO SÉCULO XVI}

são nas estruturas, nas mentalidades e nos costumes. A libertação dos Indios será uma restituição da sua liberdade natural (que não coincide com a natureza da liberdade de que sonham os filantropos do século XVIII). Os pagãos fazem parte "em potência" do Corpo Místico². T. Todorov alerta, porém para o facto que Las Casas, se afirma a igualdade de princípio de todos os povos, não se demarca da sua convição da superioridade da religão cristã, que é a sua, sendo levado a atribuir aos Indios as características dos cristãos ideais -aquilo a que Todorov chama "assimilacionismo inconsciente" ${ }^{13}$. Quer dizer, a óptica lascasiana é ainda uma óptica cristã. Nem o assimilacionismo nem o etnocentrismo são olhares "limpos" sobre o Outro. O "saber" sobre o Outro não é neutro: está ligado a posição ética que se assume e aos valores que elogiamos. E a questão que tem de colocar-se é mesmo esta: pode a descrição dos lugares, dos costumes e das gentes fazer-se de modo objectivo, sem sombra de valor?

\section{REPRESENTAÇÕES DO CORPO}

A cultura discursiva do renascimento português assenta em três quadros fundamentais: escolástico, humanista e racionalista pragmático-experimental. Silva Dias extrai daí dois campos de força e de sentido, duas hegemonias culturais: a escolástica e a humanista ${ }^{4}$. A ideia de "natureza" deflui de um destes três quadros. João de Barros e os cronistas dos descobrimentos no seu conjunto adoptam o quadro aristotélico-tomista para falar quer da natureza quer dos vícios. José de Anchieta, que inculturou como poucos o Outro no seu discurso catequético, exprime-se assim numa peça de teatro de "recebimento":

\section{Seja a maldade expulsa \\ de nossa terra. \\ Extirpe-se o mal, para o espírito de Deus dominar perenemente.}

O conflito cifra-se entre seguir os "princípios" do "diabo", ou os do "criador". Respeitar o pajé Caruara e abjurar as leis de seus pais, ou seguir as leis de Deus 5 .

\footnotetext{
2 VINCENT, ANDRÉ (1975), Las Casas Apôtre des indiens, Paris, Nouvelle Aurore.

3 TODOROV, TZVETAN (1991), Lés morales de l'histoire, Paris, Grasset, p 63.

Silva Dias, J. S. (1981), Camões no Portugal de Quinhentos, Lisboa, p. 14.

5 ANCHIETA, JOSÉ DE (1954), "Recebimento que fizerarn os índios de Guaraparim ao Padre Provincial Marçal Beliarte", in IV centenário da cidade de São Paulo. José de Anchieta, São Paulo, p. 670 ss. 


\section{JOSÉ AUGUSTO MOURÃO}

\section{O DISCURSO SOBRE A NUDEZ}

O discurso da literatura do século XVI português acerca da nudez é grandemente influenciado pelo discurso da teologia então dominante, no quadro geral da civilização dos costumes, em que novas regras de pudor se formulam. $\mathrm{O}$ nu antigo desaparecera do universo dos cristãos e a roupa é vista como uma formalidade, uma honra a que todos têm direito. Os espíritos conservavam ainda os quatro sentidos simbólicos que a Idade Média atribuía à nuditas: naturalis, evocando a humildade e a poeira de que somos feitos, temporalis, sublinhando a pobreza, virtualis, ao sublinhar a inocência, criminalis, como sinal de luxúria ${ }^{6}$. Há de resto representações do baptismo de Cristo nu, sem que tal tenha causado problemas 7 . $\mathrm{Na}$ Renascença as coisas mudaram muito, solicitando uma nova maneira de olhar o corpo. A nudez deixou de ser sinal de humildade e o corpo passou a ser visto como sinal de energia, objecto anatómico normalizado segundo critérios estéticos. Em 1559, Paulo IV ordena a Daniel de Volterra que revista a nudez dos frescos de Miguel Angelo. As folhas de videira vão singularizar os órgaos genitais atraindo o olhar sobre aquilo que querem esconder. $\mathrm{O}$ nu é agora aquele a quem se vê o sexo. A arte tem uma nova missão: imitar directamente a realidade. $O$ nu da Renascença italiana não é nem erótico nem realista, nem obsceno, é um emblema. Mudança de paradigma: do ouvir ao ver.

As concepções do século XVI sobre a vida moral e afectiva associam ou opõem o espiritualismo e o mecanismo. A cosmologia medieval funda-se no teocentrismo: os seres e as coisas definem-se em relacão a um Motor divino, as relações entre Deus e as criaturas são de natureza simbólica. Só a partir da Renascença as descobertas científicas tenderão a isolar Deus da Criação e a autonomizar a Natureza. A Natureza é boa e no seu conjunto o século XVI é optimista. No vocabulário e na sociedade deste século, aquilo que se opõe a honra é a vergonha, palavra que adquire a acepção de "timidez"8. No Brasil, a expressão "gente de vergonha" quer dizer "gente honrada". "Vergonha" designa o pejo de ser visto em estado indecente; sentimento de desgosto que resulta da ideia ou o receio da desonra. No plural, "vergonhas" designa as partes pudendas, isto é os órgãos genitais.

Na nossa cultura judeo-cristã, o termo pudor evoca simultaneamente três noções: um objecto, o corpo e a sua nudez; um sentimento, a vergonha ou pelo menos o constrangimento; uma atitude, a dissimulação ou a proteç̧ão face ao outro (do seu olhar, da sua escuta, do seu tocar). Esta concepção vai ao encontro da interpretação que o biblista dá do relato do Génesis (Gn 3, 7-10): a vergonha que o ser humano ressente em relação ao seu corpo e mais particularmente das suas "vergonhas", tor-

6 Bottomley, Frank (1979), Attitudes to de Body in Western Christendom, Londres, Lepus Books.

7 Bologne, JEAN-ClaUde (1980), Histoire de la pudeur, Paris, Olivier Orban, pp. 115, 129.

8 MATORÉ, GEORGES (1988), Le Vocabulaire et la Société du XVIè siècle, Paris, PUF, p. 73 ss. 
nou-se o traço gravado em cada um da transgressão originária que atinge doravante toda a consciência humana. Enquanto atitude de reserva, de modéstia e de discreção, o pudor seria a indispensável compensação numa relação com o corpo que se tornou difícil, porque com uma forte carga negativa, que implica $a$ contrario que o seu desvelamento, total ou parcial, é ao mesmo tempo um mal e uma fonte de desordem. É esta carga, este fenómeno iminentemente cultural, que os nossos escritores transportam no seu discurso sobre a nudez.

Para Gândavo, o índio é inconstante, desonesto e dado a sensualidade, ainda que em seu ajuntamento os machos com as fêmeas têm o devido resguardo, e nisto mostram ter alguma vergonha (História, p. 102). A lei da natureza é o diapasão para avaliar da justeza ou da maldade dos comportamentos. Assim, os índios entregam-se aos vícios como se neles não houvera razão de homens (e daí a maldade desses actos), e ao mesmo tempo, na parte que toca a fazendas, pompas e opiniões de honra, eles vivem justamente e conforme à lei da natureza (Ibidem, pp. 105-106). Zurara, agora em relação aos mouros, classifica o seu modo de viver como semelhante àas bestas. O cativo participa de uma categoria de Homem, Bestial ou Selvagem. A fórmula aristotélico-tomista da vida "razoável" e a nocão de bestialidade estão subjacentes, como referencial, na avaliação do africano por Zurara9.

A primeira representacão dos Indios do Brasil chega-nos através de uma Adoracão dos Magos, um dos catorze painéis de um políptico pintado para o altar mór da catedral de Viseu (1500-1506). Neste painel o rei mago Baltazar, que habitualemente se representa como negro, aparece aqui na figura de um Indio, não nu, mas vestido a europeia. A. Margarido interpreta este facto, não apenas como reaccão do sentimento religioso a nudez mas porque a nudez representa um facto de selvajaria ${ }^{10}$.

O encontro com o Outro avalia-se nos escritos dos cronistas portugueses pelo grau de transgressão das práticas e das normas que são as suas: ocidentais e cristãs. É assim em relação aos códigos alimentare ${ }^{11}$, é assim em relação a cor e em relacão a nudez: Não podendo reduzir o Outro àsua norma, o discurso europeu apenas pode taratologizá-lo' ${ }^{12}$.

O etnocentrismo de Zurara é visível no comentário que faz, com intenções claramente moralizadoras, acerca daqueles que não querem sujeitar-se às regra do jejum, ou acerca da sua concepção do tempo: todo seu viço é folga sem trabalho. Em forni-

\footnotetext{
9 SILVA HORTA, JOSÉ DA (1991), "Primeiros olhares sobre o Africano do Sara Ocidental à Serra Leoa (meados do século XV-inícios do século XVI)", in $O$ confronto do olhar, Lisboa, Caminho, p. 86.

10 MARGARIDO, AlFredo (1984), "La vision de l'autre (Africain et Indien d'Amérique) dans la Renaissance portugaise", in L'Humanisme Portugais et L'Europe, FCG, Centre Culturel Portugais, Paris, p. 524.

11 EANES DE ZURARA, Gomes (1973), Crónica de Guiné, Livraria Civilização, p. 158.

12 MARGARIDO, ALFREDO, art. cit, p. 554.
} 


\section{JOSÉ AUGUSTO MOURÃO}

zio põem toda sua bemaventurança, que não teem ensinança de lei, somente creem que ha ai Deus (Zurara, op. cit., p. 340).

A carta de Cristóvão Colombo aos reis católicos é importante para recolocar a carta de Pero Vaz de Caminha a D. Manuel no contexto dos estereótipos culturais da época, neste ponto acerca da nudez: as pessoas desta ilha e de todas as outras que descobri ou de que tive conhecimento andam todas nuas, homens e mulheres, como as suas mães as deram à luz, embora algumas mulheres se cubram num único sítio do corpo com uma folha de erva ou um trapo de algodão que fazem para este efeito $^{13}$. Ou, na versão de Pêro Vaz de Caminha: A feição deles é serem pardos, maneira d'avermelhados, de bons rostos e bons narizes, bem feitos. Andam nus, sem nenhuma cobertura, nem estimam nenhuma cousa cobrir nem mostrar suas vergonhas. E estão acerca disso com tanta inocencia como têm em mostrar o rosto ${ }^{14}$.

Da sexualidade pouco se diz nestas crónicas. No seu Diário de bordo da viagem de Vasco da Gama, Alvaro Velho refere uma informação relativa as práticas físicas dos Africanos da costa oriental. Os homens desta costa usavam estojos penianos, e Alvaro Velho consegue obter um destes estojos, dando disso relato, sem comentários $^{15}$. A informação de Alvaro Velho constava da crónica de Damião de Góis ${ }^{16}$. Antes que o conde de Tentúgal, que dispunha do manuscrito, tenha vindo à liça para criticar esta passagem, já Damião de Góis a suprimira: A informação sobre os objectos de civilização, o corpo e a sexualidade do Outro era julgada suficientemente indecente para que fosse expurgada do texto ${ }^{17}$. O estojo sublinha, evidentemente, a nudez, mas sobretudo o espectáculo das partes sexuais masculinas. O que não deve ser descrito, por impudico.

Caminha tem, relativamente à nudez dos índios, uma posição neutra, como um elogio da inocência: Ali andavam entre eles três ou quatro moças, bem moças e bem gentis, com cabelos muito pretos, compridos, pelas espáduas; e suas vergonhas tão altas e tão çarradinhas e tão limpas das cabeleiras que de as nós muito bem olharmos ñão tínhamos nenhuma vergonha (Pêro Vaz de Caminha, op. cit., p. 45).

Esta ausência de vergonha deve-se ao facto que estas moças, como a totalidade dos Indios, se depilarem, eliminando dos seus corpos os pêlos -uma marca importante na

13 Colombo, Cristóvao (1980), La découverte de l'Amérique, vol. II, Relation de voyage. 14931504, Paris, Maspero, La découverte, pp. 51-52; La carta de Colón anunciando el Descubrimiento del Nuevo Mundo, 15 febrero-14 marzo, 1499, Madrid, Gráficas Yagües, s.l., 1961.

14 VAZ DE CAMINHA, PÊRO (1974), Carta a el-rei d. Manuel, Lisboa, Imprensa Nacional-Casa da Moeda, p. 37.

15 Roteiro da Primeira Viagem de Vasco da Gama (1497-1499) (1969), Lisboa, Agência Geral do Ultramar, p. 7.

16 GóIS, DAMIÃo DE (1926), Crónica do Felicissimo rei D. Manuel, Coimbra, Imprensa da Universidade, p. 70.

17 MARGARIDO, A., art cit, p. 514. 
tradição judeo-cristã. Zurara conta da dificuldade de se "filharem" os Guinéus pelo facto de andarem nus e não terem cabelos senão mui curtos (Zurara, op. cit., p. 319). A relação entre os cabelos, a força física e o poder genésico interessa de modo especial aos viajantes deste tempo. Donde vem esta inquitação frente ao corpo nu? Zurara abre-nos algumas pistas acerca da apresentação da nudez: as mulheres vestem alquices que são assim como mantos, com os quaes somente cobrem o rostros, e por ali entendem que acabam de cobrir toda sua vergonha, que os corpos trazem todos nus. Por certo, diz aquele que ajuntou esta história, que esta é uma das cousas por que homem pode conhecer sua grande bestialidade, que se alguma pequena razão entre eles houvesse, seguiriam a natureza, cobrindo aquelas partes somente que ela mostrou que deviam ser cobertas, que vemos naturalmente que em cada um daqueles lugares vergonhosos pos cerco de cabelos, mostrando que os queria esconder; $e$ ainda têm alguns naturaes que se leixarem assim aqueles cabelos, que tanto crescerão, até que escondam todolos lugares de vossa vergonha (Zurara, op. cit., p. 323-324).

Não é indiferente que as mulheres sejam assim apresentadas, sem razão e sem discerniment;o relativamente a nudez e à mensagem divina. Já em Pêro Vaz de Caminha se estabelece outro tipo de relação entre a ausência de desejo e as práticas de depilação. Aqui nada proíbe que se olhe a nudez e a formosura da moça índia, tão bem feita e tão redonda e sua vergonha, que ela não tinha, tão graciosa, que a muitas mulheres de nossa terra, vendo-lhe tais feições, fizera vergonha, por ñão terem a sua como ela (Pêro Vaz de Caminha, op. cit., pp. 46-47) ${ }^{18}$. Noutro passo ainda, refere o nosso cronista: Também andavam entre eles quatro ou cinco mulheres moças, assim nuas que não pareciam mal... E suas vergonhas tão nuas e com tanta inocencia descobertas que não havia aí nenhuma vergonha (ibidem: 56).

A perfeição física dos indios impressionou muito não só os nossos cronistas, mas igualmente Jean de Léry e Las Casas. Não era só a beleza, mas a nudez inocente que inquietava a quem vinha marcado por uma suspeição relativamente ao corpo e à inocência dos seus movimentos. A interpretação que se faz da nudez, vai da condenação que dela Zurara, por exemplo faz, dada a conexão entre os pêlos e o pecado, e o elogio que da mesma faz Caminha, pela presença da depilação.

\section{DA TANGA AS TÚNICAS DE PELE}

No confronto do olhar sobre a nudez e sobre a vergonha que tal estado deveria suscitar, o cronista conclui de modo geral que aquele que assim vê, disso não cura, logo disso não se envergonha. Porque o sentimento de vergonha nasce da ideia da

18 Veja-se, a propósito da nudez e da formosura das mulheres índias, o que JEAN DE LÉRY (1960) escreve na sua Viagem a Terra do Brasil, S. Paulo, Martins Editora, p. 111. 


\section{JOSÉ AUGUSTO MOURÃO}

corrupção da natureza humana decaída. Fundamentalmente da mundividência cristã ocidental que considera impudica a nudez. $O$ que cochila por trás desta visão etnocêntrica acerca dos costumes do Outro é uma teologia eivada do trágico da existência (de que a Reforma é o mais alto sinal) e a reinterpretacão do relato do Génesis em termos de pessimismo antropológico. João de Barros, no seu Diálogo da Viciosa Vergonha, uma obra deliberadamente didáctica e moralizadora, ilustra bem a moral dos humanistas portugueses do século XVI. A definição que dá da vergonha reportanos quer a Aristóteles quer a S. Tomás. Se a vergonha é dor, é porque se gera da memória do pecado cometido, em clara conexão com o capítulo terceiro do Génesis. Uma outra vergonha, que corresponde a turvação e tempo presente, filha da humildade, caracteriza aqueles em cuja alma reina inocência e pudicícia virginal (Diálogo, p. 416). Enfim, uma terceira espécie de vergonha, filha do temor e que respeita ao futuro, feita de palavras ou feitos desonestos e de que se pode temer que dái venha infâmea ou represensão. Natural nos mancebos e contra a naturezanos velhos, esta paixão tem nos olhos a morada. Ficamos" a saber que as pessoas em quem é mais natural a vergonha são, segundo este autor, aquelas a quem a nobreza do sangue e a compleixão mais favorece (Diálogo, p. 430).

Fílon de Alexandria parece ter sido o primeiro a interpretar a narrativa do "pecado original" do Génesis em termos de delito de ordem sexual, no que foi seguido por dois ou três doutores cristãos antigos. Na teologia cristã há duas correntes, uma agostiniana, que continua a pensar nos termos de Fílon, e outra tomasiana, para quem o homem, antes do seu "pecado" podia certamente fazer um uso normal das suas capacidades sexuais.

Colocado no começo de um percurso, o estado de nudez deve poder ler-se no relato bíblico (Gen. 2,18) como uma falta que exige uma transformação. É a instancia enunciativa que nota a "nudez" e que regista a ausência de "vergonha". No conjunto do relato este estado provocará uma busca com vista a preencher esta falta: o sujeito vai sucessivamente adquirir o "saber da sua nudez" $(3,7)$ e o "conhecimento do bem e do mal" $(3,22)$, sendo estas aquisições marcadas por uma indumentária diferente $(3,7$ e 3,21$)$. O sema nuclear do lexema "nus" comporta a ideia de uma coisa sem cobertura e sem ornamento, de um ser "tabula rasa". A nudez dos "dois" (componentes do adão) corresponde a uma estabilidade num estado que nada devia perturbar se não fosse o desenvolvimento do mundo criado e o desenrolar duma história. Apesar deste ponto zero os "dois" não sentem "vergonha". A figura da "vergonha" está ligada à da "nudez" como uma figura do saber sobre um estado prático do casal adâmico. A ausência de vergonha assinala que a falta não é reconehcida como tal pelos "dois" membros do casal. A lei conjugal exige um fazer eventual no casal sexual (deixar as suas origens e ligar-se numa só carne).

$O$ recurso a folhas cozidas não tem como função esconder a nudez: significa que doravante a nudez é conhecida. A intervenção de Javé Eloim acontece para arrancar 


\section{A MORALIZAÇÃO DAS VERGONHAS NATURAIS NA LITERATURA PORTUGUESA DO SÉCULO XVI}

o casal adâmico da sua quietude de "estar só" e manifesta-se também para impedir que o casal se refugie no saber da sua nudez (nas suas tangas de folhas de figueira) para o fazer passar ao conhecimento do bem e do mal (numa túnica de pele animal). Uma interpretação semiótica deste texto vai no sentido de dizer que o casal comendo o fruto tomou consciência da sua nudez e quis regressar ao seu meio vegetal, como se recusasse este acesso à consciência. Ser mãe de toda a vida não é ainda ter gerado um filho (cf. 4,1), mas ter desencadeado o processo do agir, ter feito passar o casal da nudez do ser a vitalidade da acção, que arrasta consciência, responsabilidade e conhecimento do bem e do mal. Ou ficava na sua nudez -sem actividade e sem vidaou decidia viver e tomava ao mesmo tempo consciência da sua nudez (= mortalidade). Eles sabem que viver étambém morrer. $O$ tema da nudez desenvolve o primeiro aspecto do saber como ciencia do mal. Comer a maçã desencadeia o ver, que desencadeia o saber e o dizer-verdadeiro. A verdade do que eram tem um nome, nudez, que designa uma diferenca não dizível que faz falar, como faz fazer tangas. $\mathrm{O}$ consumo da maçã transmite-lhes uma competência eidética que os faz ver e ver-se; a seguir, uma competência cognitiva leva-os a saber (que estão nus). A operação do ver instalará uma alética, do mesmo modo que a operação do saber instala uma epistémica. A nudez surge então como episteme trocada entre Adão e Eva que de comum acordo se pôem a coser folhas de figueira para se cobrir com tangas: eles compreendem na sua episteme que são olhados um pelo outro e que portanto o seu próprio olhar é olhado pelo outro. Como P. A. Brandt observa, "a diferença sexual impede a identificação das visões... a nudez é um estado veridictório pós-epistémico, no sentido em que o sujeito nu, ao assumir o veredicto sobre o outro, assume ao mesmo tempo a impossibilidade de partilhar uma mesma verdade, a perda de verdade que tem lugar no seu dizer"119.

Perdido o sentido do recurso à nudez como despojamento, acentuam-se agora os códigos do pudor: os olhos são os pequenos libertos, que correm por aqui e por ali $e$ andam a procura de doenças em determinados objectos, ensina um padre de Liege ${ }^{20}$.

Pêro Vaz de Caminha, interroga os corpos nus dos índios como uma mensagem: como decifrar estes corpos dentro dos nossos códigos vestimentares? Só que não há código para passar do nível das relações corporais complementares a linguagem; não há passagem codificada entre o corpo significante e a ordem icónica. Qualquer passagem de um nível ao outro está marcada pela indeterminacão, como a passagem do sonho ao seu relato.

Concluamos. A analogia criada por Jorge de Lima entre o canto gregoriano, monódico e pobrinho com a música tupi parece-me aqui de valor exemplar. A música

19 AAGE BRANDT, PER (1992), La Charpente modale du sens, Aarhus Univ. Press J. Benjamins Publ. Comp., p. 139.

20 BOLOGNE, JEAN-ClaUde, op. cit, pp. 201, 307. 


\section{JOSÉ AUGUSTO MOURÃO}

tupi estaria de acordo com a sua desintencão, a sua nudez. Ora, como vimos, a nudez era boa quando significava o despojamento e a humildade. Inocente. Mas a nudez não será permitida por ser, na óptica do colonizador, contra-natura. Podia-se argumentar com Aristóteles, segundo o qual das coisas que nos vêm por natureza, nem somos louvados nem vituperados (Ética, cap. XVI, 1114 a 21). Mas será em nome de Aristóteles cristianizado que o seu estado de nudez será moralizado. Pode interpretar-se esta moralização como inquietude, antes de mais. A inquietude reflecte uma agitação antes da euforia ou da disforia. Este estado suspende a polarização, interditando qualquer evolução das tensões da foria, e obstaculiza a formação das "valências". Oscila-se então entre "atracção" e "repulsa". Creio que a interpretacção da nudez que fazem os nossos escritores de quinhentos é fundamentalmente do tipo da inquietude. A imagem que têm do corpo próprio modelado pelo "habitus social" projectam-na agora sobre o Outro que mal compreendem, moralizando os seus costumes numa escala de conformidade que permite concluir do excesso ou da insuficiência desses costumes. O que, em último caso a moralização tenta controlar é o contágio passional. Esse contágio será de facto controlado sob a forma da parenética ou da legislação civil.

Respeitar alguém é renunciar a vontade própria de o fazer ser como eu quero ou de lhe fazer o que eu quero. Nem em pensamento nem em acto. $\mathrm{O}$ contrário do respeito é o desprezo que consiste em tratar o outro a seu bel-prazer.

A vergonha segue-se à negação ou à recusa do espírito na carne. Da dissolução da carne e do espírito. Impedidos de procurar/encontrar a sua identidade na palavra do Outro do desejo que não é pensável nem imaginável, são os cronistas que devem ser acusados de falta de pudor. Fechado na torre da sua imagem, o Homem ocidental descobre que está no vazio e despojado das vestes da aliança. Foi essa aliança que faltou para abrir a porta ao discernimento entre o verdadeiro e o falso no encontro. Faltou ao encontro inquietante do Outro a conversão do olhar. Porque a nudez do corpo é sempre uma objectividade sem defesa: Todos andam nus, assim homens como mulheres, e não têm género nenhum de vestido e por nenhum caso verecundant; antes parece que estãono estado de inocência nesta parte (Fernão Cardim, Do Princípio, p. 167). Não se podia vestir a música daquele despido, mas só enfeitá-la. Porque vestir-se é dissimular a sua objectividade, reclamar o direito de ver sem ser visto.

A fundação do Império assenta na empresa das línguas, como Nebrija e João de Barros sustentavam. O processo através do qual o corpo significante aparece ao lado da lei social é inseparável da emergência da imagem do corpo próprio e da intervenção massiva da linguagem: a constituição do corpo próprio (no sentido da propriedade) não se distingue da constituição do corpo limpo (no sentido da limpeza). Que corpo fica (próprio e limpo) quando a imagem de nós se perde ou no-la roubam? Todas as tentativas feitas para "vestirem" o corpo do ameríndio saíram frustradas: Agora já andam alguns vestidos, assim homens como mulheres, mas estimam-no tão 
pouco que o não trazem por honestidade, mas por cerimónia, e porque lho mandam trazer, como se vê bem, pois alguns saem de quando em quando com uma jornes que lhes dão pelo umbigo sem mais nada, e outros somente com uma carapuça na cabeça, e o mais vestido deixam em casa, escreve Fernão Cardim (Do incípio, p. 168).

Encontrar o Outro nos seus usos e costumes, na sua cultura, entrar na partilha de códigos e de vozes, sem se confiscar, sem impor os seus próprios como norma a seguir, era coisa impensável no século XVI. Donde os desencontros a todos os níveis: da sua comida, da sua idolatria ou da sua luxúria. O juízo sobre cada um destes tópicos varia conforme o grau de repulsa ou de atração que os códigos transportados propiciam. $\mathrm{O}$ que atenua em muito a rigidez dos julgamentos é ainda a indulgência que se tem com as crianças que não alcançaram ainda o estado da razão. $O$ primitivo estado de inocência em que se vê o índio, é para o colonizador ainda um estado de promessa: de que, com o tempo, ele chegará um dia à imagem e semelhança de si próprio. Invenção do corpo ou domesticacão do Outro? 